\title{
Alternating Binaphthyl-Thiophene Copolymers: Synthesis, Spectroscopy, and Photophysics and Their Relevance to the Question of Energy Migration versus Conformational Relaxation
}

\author{
J. Pina, ${ }^{\dagger}$ J. Seixas de Melo, ${ }^{*}{ }^{\dagger}$ H. D. Burrows, ${ }^{\dagger}$ A. L. Maçanita, ${ }^{\ddagger}$ F. Galbrecht, ${ }^{\S}$ \\ T. Bünnagel, ${ }^{\S}$ and U. Scherf ${ }^{\S}$ \\ Department of Chemistry, University of Coimbra, Rua Larga, 3004-535 Coimbra, Portugal, \\ Departamento de Engenharia Química e Biológica, Centro de Química Estrutural, Instituto Superior \\ Técnico, Av. Rovisco Pais, s/n. Lisboa, Portugal, and Makromolekulare Chemie, Bergische Universität \\ Wuppertal, Gaussstr. 20, 42097 Wuppertal, Germany
}

Received October 24, 2008; Revised Manuscript Received December 30, 2008

\begin{abstract}
The synthesis and a comprehensive spectroscopic and photophysical study are presented of four alternating binaphthyl-oligothiophene copolymers (DP: 10-15 repeat units) in solution at room and low temperature and in the solid state (thin films). Detailed results are presented on absorption, emission, and triplet-triplet absorption spectra together with all relevant quantum yields (fluorescence, intersystem crossing, internal conversion, and singlet oxygen formation), excited-state lifetimes, and singlet and triplet energies. From these, several conclusions can be drawn. First, the main deactivation channels for the molecules in solution are the radiationless processes $\left(S_{1} \rightarrow S_{0}\right.$ internal conversion and $S_{1} \rightarrow T_{1}$ intersystem crossing). Second, in the solid state the fluorescence quantum yields are smaller than those in solution. From time-resolved fluorescence decays in the picosecond time domain, three decay components are seen: a fast decay (40-60 ps) at short wavelengths, which becomes a rising component at longer wavelengths, an intermediate decay component (330-477 ps) associated with an ensemble of isolated segment-like units, which is dominant at the initial part of the emissive spectra and progressively decreases for longer emissions, and a third exponential related to the emission of the fully relaxed polymer. Together with steady-state anisotropy studies, this is discussed in terms of the possibilities of energy migration/transfer along the polymer chain and of the conformational (torsional) relaxation of the systems studied.
\end{abstract}

\section{Introduction}

Conjugated organic polymers are playing a major role within the developing field of plastic electronics, due in particular to their applications in light-emitting diodes, thin film transistors, photovoltaic devices, sensors, etc. ${ }^{1-3}$ Considerable research effort has been devoted to the improvement of the light-emitting properties and color tuning of photoluminescence devices involving conjugated polymers. ${ }^{4}$ One approach for achieving this goal involves copolymerization with chromophores displaying high fluorescence emission yields and good electronic properties.

Pure binaphthyl enantiomers are commercially available. Proper substitution of the binaphthyl core has provided suitable monomers with different side chains in $2,2^{\prime}$-position for our copolymerization experiments. ${ }^{5,6}$ In this study, the synthesis of fluorescent alternating copolymers containing both binaphthyl and oligothiophene moieties will be described. Oligothiophenes have been chosen as building blocks because of their unique properties, such as high (photo)stability and good hole transport properties. ${ }^{7,8}$ However, oligothiophenes, and more particularly polythiophenes, display low fluorescence quantum yields due to the high density of vibrational modes of the excited-state species that can lead to other modes of decay than photon emission (such as thermal decay and intersystem crossing), ${ }^{9}$ in addition to their efficient intersystem crossing induced by the heavy atom effect of the sulfur atom. ${ }^{10}$ As indicated above, it may be possible to overcome the low fluorescence quantum yields and improve the emission efficiency of oligothiophenes

\footnotetext{
* Corresponding author: e-mail sseixas@ci.uc.pt; Fax 00351239827703.

†niversity of Coimbra.

Instituto Superior Técnico.

$\S$ Bergische Universität Wuppertal.
}

by copolymerization with highly fluorescent moieties. This approach can decrease the vibrational freedom of the singlet excited state and favor the excited-state radiative channel. In addition, the incorporation of nonplanar units, such as binaphthyl, in the polymer backbone should suppress interchain interactions, which could prevent polymer chains from packing, thereby reducing self-quenching processes and thus improving the fluorescence quantum efficiency. ${ }^{11-13}$ In the case of binaphthyl, the pseudo-orthogonal nature of this chromophore (with the dihedral angle between the two naphthalene units ranging from $60^{\circ}$ to $120^{\circ}$ ) should suppress the crystallization and facilitate the formation of an amorphous glassy state. ${ }^{12}$

One important current topic of discussion in the field of conjugated organic polymers is the exact nature of fast relaxation processes occurring following excitation of the polymer. ${ }^{14-16}$ The possibilities which have been suggested include intrachain and interchain energy transfer, ${ }^{17}$ together with more localized phenomena such as intramolecular vibrational relaxation ${ }^{18}$ and/ or conformational (torsional) relaxation within the polymer skeleton. ${ }^{16,19,20}$ In general, conjugated polymers typically contain between 10 and 1000 repeat units, ${ }^{21}$ and consequently intrachain processes may involve different conjugation segments of the polymer, which may result from conformational defects, ${ }^{22}$ such that they are likely to be important with isolated chains, whereas interchain processes, which are particularly relevant in the solid state, involve different polymer units/chains. These processes may be interdependent. ${ }^{15}$ Intrachain processes depend on the size of the polymer backbone chain and consequently on the number of conjugated segments (chromophores) along the chain. The existence of conformational defects is often responsible for the (de)localization of $\pi$-electrons onto individual segments. Depending on the different chromophore structures, each segment can emit within the same polymer. 
Two distinct explanations have been given to the fast component in the fluorescence decays of organic conjugated polymers; either it results from resonance energy transfer between different conjugated segments, or it is due to conformational relaxation within the polymer backbone. A differentiation between the relative contributions of these two competitive processes to the fast component decay can be made by investigating oligomeric compounds where energy transfer is absent. ${ }^{16}$ In general, it is accepted that energy transfer can occur between different chromophores within the polymer chain, and these processes can be faster or slower, ranging from values $<1 \mathrm{ps}$ to some hundreds of $\mathrm{ps}$, depending on the relative energy of these segmental units. ${ }^{14}$

In the present study, we have investigated four polymers possessing a relatively small number of binaphthyl-oligothiophene repeat units $(10-15)$. For this reason, and due to the function of the binaphthyl moieties as effective conjugation barriers, the extent of intrachain energy transfer between the conjugated segments should be drastically reduced. In this particular case, the shortest living component of the fluorescence decay should preferentially be associated with conformational relaxation processes. Thus, the present investigation of the photophysics and time-resolved fluorescence decay profiles in solution of four alternating binaphthyl-oligothiophene copolymers may provide new insights into the fluorescence relaxation phenomena in conjugated polymers. In addition, thiophenecontaining copolymers are now important materials for solar cell $^{3,23}$ and charge transport ${ }^{24}$ applications, and understanding of the photophysical and energy migration properties is also relevant for these.

\section{Experimental Section}

Materials. Unless otherwise indicated, all starting materials were purchased from commercial sources (Aldrich, Fischer, EM Science, Lancaster, ABCR, Strem) and used without further purification. All reactions were assembled under an inert atmosphere either in a screw-capped vial or in a resealable Schlenk tube. Analytical thinlayer chromatography (TLC) was performed on Merck silica gel plates with F-254 indicator. Visualization was accomplished by an ultraviolet lamp (254 nm). Silica gel column chromatography was carried out with silica gel (230-400 mesh) from EM Science. ${ }^{1} \mathrm{H}$ and ${ }^{13} \mathrm{C}$ NMR spectra were recorded on a Bruker ARX 400 spectrometer. Chemical shifts $(\delta)$ are reported in parts per million (ppm) using residual solvents protons as internal standards. The coupling constants are reported in hertz $(\mathrm{Hz})$. Splitting patterns are designated as s (singlet), d (doublet), t (triplet), q (quartet), bs (broad singlet), m (multiplet), and bm (broad multiplet). Low-resolution mass spectrometry was obtained on a Varian MAT 311A operating at $70 \mathrm{eV}$ (electron impact, EI) and reported as $\mathrm{m} / \mathrm{z}$ and percent relative intensity. Molecular weight determinations via gel permeation chromatography (GPC) were performed using a Spectra 100 GPC column ( $5 \mu \mathrm{m}$ particles) eluted with THF at $30{ }^{\circ} \mathrm{C}$ (flow rate of $1 \mathrm{~mL} \mathrm{~min}{ }^{-1}$ and concentration of polymer: ca. $1.5 \mathrm{~g} \mathrm{~L}^{-1}$. The calibration was based on polystyrene standards with narrow molecular weight distribution. Listed $M_{\mathrm{n}}$ values are given in $\mathrm{g}$ $\mathrm{mol}^{-1}$. Microwave-assisted synthesis were performed using a CEMDiscovery monomode microwave utilizing a IR-temperature sensor, magnetic stirrer, and sealed $10 \mathrm{~mL}$ glass vials $\left(110^{\circ} \mathrm{C}, 12 \mathrm{~min}\right.$, $300 \mathrm{~W})$. The synthesis of 5,5'-bis(trimethylstannyl)-2,2'-bithiophene, ${ }^{25} 5,5^{\prime \prime}$-bis(trimethylstannyl)-2,2':5,2"'-terthiophene, ${ }^{25}$ and $6,6^{\prime}$-dibromo-2,2'-bis(octyloxy)-1,1'-binaphthyl (1) ${ }^{26}$ are reported elsewhere.

Monomer Synthesis. 2,2'-Bis(octyloxy)-1,1'-binaphthyl (BNp). 1,1'-Binaphthyl-2,2'-diol (10.0 g, $34.5 \mathrm{mmol})$ and 1-bromooctane ( $30 \mathrm{~mL}, 173 \mathrm{mmol}$ ) were dissolved in anhydrous $\mathrm{CH}_{3} \mathrm{CN}(200 \mathrm{~mL})$ under an argon atmosphere and refluxed for $24 \mathrm{~h}$. The solution was allowed to cool down to room temperature and water added. The product was extracted with petroleum ether and the organic phase washed with brine, dried over magnesium sulfate, and the solvent removed in vacuum to yield the desired product $(13.2 \mathrm{~g}$, $75 \%) .{ }^{1} \mathrm{H}$ NMR $\left(400 \mathrm{MHz}, \mathrm{CDCl}_{3}, 25{ }^{\circ} \mathrm{C}\right): \delta=7.85(\mathrm{~d}, J=9.0$ $\mathrm{Hz}, 2 \mathrm{H}), 7.78(\mathrm{~d}, J=8.1 \mathrm{~Hz}, 2 \mathrm{H}), 7.34(\mathrm{~d}, J=9.0 \mathrm{~Hz}, 2 \mathrm{H}), 7.24$ $(\mathrm{m}, 2 \mathrm{H}), 7.12(\mathrm{t}, J=7.4,7.4 \mathrm{~Hz}, 2 \mathrm{H}), 7.07(\mathrm{~d}, J=8.1 \mathrm{~Hz}, 2 \mathrm{H})$, 3.85 (bm, 4H), 1.39-1.26 (bm, 4H), 1.22-1.09 (bm, 4H), 1.09-0.71 (bm, 22H) ppm. $\left.{ }^{13} \mathrm{C} \mathrm{NMR} \mathrm{(100} \mathrm{MHz,} \mathrm{CDCl}_{3}, 25{ }^{\circ} \mathrm{C}\right)$ : 154.9, 134.4, 129.5, 129.3, 128.1, 126.2, 125.9, 123.7, 120.9, 116.4, 70.2, 32.0, 29.7, 29.43, 29.42, 25.9, 23.0, $14.5 \mathrm{ppm}$.

(R)-6,6'-Dibromo-2,2'-bis(4-octylbenzyloxy)-1,1'-binaphthyl (2). (R)-6,6'-Dibromo-1,1'-binaphthyl-2,2'-diol (1.0 g, $2.3 \mathrm{mmol})$ and 1-(bromomethyl)-4-octylbenzene (1.95 g, $6.9 \mathrm{mmol}$ ) were dissolved in anhydrous $\mathrm{CH}_{3} \mathrm{CN}(100 \mathrm{~mL})$ under an argon atmosphere and refluxed for $24 \mathrm{~h}$. The solution was allowed to cool down to room temperature and water added. The product was extracted with petroleum ether and the organic phase washed with brine, dried over magnesium sulfate, and the solvent removed in a vacuum. The crude product was purified by column chromatography on silica gel ( $n$-hexane:ethyl acetate, 95:5) to yield the desired product (1.1 g, 56\%). ${ }^{1} \mathrm{H}$ NMR $\left(400 \mathrm{MHz}, \mathrm{C}_{2} \mathrm{D}_{2} \mathrm{Cl}_{2}, 25{ }^{\circ} \mathrm{C}\right): \delta=7.97(\mathrm{~d}, J=$ $2.0 \mathrm{~Hz}, 2 \mathrm{H}), 7.79(\mathrm{~d}, J=9.1 \mathrm{~Hz}, 2 \mathrm{H}), 7.40(\mathrm{~d}, J=9.1 \mathrm{~Hz}, 2 \mathrm{H})$, $7.21(\mathrm{dd}, J=9.1,2.0 \mathrm{~Hz}, 2 \mathrm{H}), 6.93(\mathrm{~d}, J=9.1 \mathrm{~Hz}, 2 \mathrm{H}), 6.86(\mathrm{~d}$, $J=8.0 \mathrm{~Hz}, 4 \mathrm{H}), 6.75(\mathrm{~d}, J=8.0 \mathrm{~Hz}, 4 \mathrm{H}), 4.91(\mathrm{~s}, 4 \mathrm{H}), 2.42(\mathrm{~m}$, 4H), 1.45 (m, 4H), 1.19 (bm, 23H), $0.80(\mathrm{~m}, 3 \mathrm{H}) \mathrm{ppm} .{ }^{13} \mathrm{C} \mathrm{NMR}$ $\left(100 \mathrm{MHz}, \mathrm{C}_{2} \mathrm{D}_{2} \mathrm{Cl}_{2}, 25{ }^{\circ} \mathrm{C}\right): 154.8,142.7,134.4,132.8,130.7$, 130.1, 129.9, 128.9, 128.6, 127.5, 127.0, 120.6, 117.8, 117.5, 71.6, 35.9, 32.2, 31.7, 29.7, 29.5, 23.0, 19.5, 14.5 ppm.

Polymer Synthesis. General Procedure for MicrowaveAssisted Stille-Type Polymerizations. Bis(trimethylstannyl)oligothiophene (1 equiv), the binaphthol derivative (1 equiv), $\mathrm{PdCl}_{2} \mathrm{dppf}$ ( 0.1 equiv), and $\mathrm{KF}$ (10 equiv) were added to a $10 \mathrm{~mL}$ vial under glovebox conditions (Scheme 1). Anhydrous and degassed toluene $(2 \mathrm{~mL})$ and anhydrous DMF (1 mL) were added, and the solution was irradiated with microwaves $(300 \mathrm{~W}$, maximum temperature) for $9 \mathrm{~min}$. The reaction mixture was diluted with chloroform and washed with $2 \mathrm{M} \mathrm{HCl}$, saturated aqueous NaEDTA, and $\mathrm{NaHCO}_{3}$ solutions. The organic phase was dried over $\mathrm{Na}_{2} \mathrm{SO}_{4}$ and the solvent removed. The residue was dissolved in chloroform, precipitated into methanol, and filtered. The solid material was extracted for 2 days in a Soxhlet apparatus with acetone; the resulting polymer was collected and dried under vacuum.

Poly[6,6'-(2,2'-dioctyloxy)binaphthyl]-alt-2,5-bithienylene (BNp 2 2). The general procedure was followed using 6,6'-dibromo-2,2' bis(octyloxy)-1,1'-binaphthyl (80 mg, $0.120 \mathrm{mmol}$ ), 5,5'-bis(trimethylstannyl)-2,2'-bithiophene (59 mg, $0.120 \mathrm{mmol}$ ), $\mathrm{PdCl}_{2} \mathrm{dppf}$ (9 mg, $0.012 \mathrm{mmol})$, and KF (70 mg, $1.197 \mathrm{mmol})$. Yield: $17 \%$. GPC (vs polystyrene standards in THF): $M_{\mathrm{n}}=4930, M_{\mathrm{w}} / M_{\mathrm{n}}=$ 1.7. ${ }^{1} \mathrm{H}$ NMR $\left(400 \mathrm{MHz}, \mathrm{C}_{2} \mathrm{D}_{2} \mathrm{Cl}_{2}, 80{ }^{\circ} \mathrm{C}\right): \delta=8.11-7.71(\mathrm{~m}$, $4 \mathrm{H}), 7.56-6.94(\mathrm{~m}, 10 \mathrm{H}), 4.02-3.67(\mathrm{~m}, 4 \mathrm{H}), 1.68-0.55(\mathrm{~m}, 30 \mathrm{H})$ ppm. ${ }^{13} \mathrm{C}$ NMR (100 MHz, $\left.\mathrm{C}_{2} \mathrm{D}_{2} \mathrm{Cl}_{2}, 80{ }^{\circ} \mathrm{C}\right): 155.3,143.9,136.8$, 134.0, 129.7, 129.6, 129.4, 129.2, 126.6, 126.0, 124.8, 124.5, 124.4, $124.0,121.1,120.6,117.1,99.8,70.0,32.0,29.7,29.5,26.0,23.0$, $14.5,11.3 \mathrm{ppm}$.

Poly [6,6'-(2,2'-dioctyloxy)binaphthyl]-alt-2,5-terthienylene [(BNpo3]. Following the general procedure $(R)-6,6^{\prime}$-dibromo-2,2'-bis(octyloxy)-1,1'-binaphthyl (60 mg, $0.090 \mathrm{mmol}), 5,5^{\prime \prime}$-bis(trimethylstannyl)-2.2':5,2"-terthiophene (52 mg, $0.090 \mathrm{mmol}), \mathrm{PdCl}_{2} \mathrm{dppf}(7 \mathrm{mg}$, $0.009 \mathrm{mmol}$ ), and $\mathrm{KF}$ (52 $\mathrm{mg}, 0.898 \mathrm{mmol})$ were reacted. Yield: $62 \%$. GPC (vs polystyrene standards in THF): $M_{\mathrm{n}}=2750, M_{\mathrm{w}} / M_{\mathrm{n}}$ $=2.9 .{ }^{1} \mathrm{H} \mathrm{NMR}\left(400 \mathrm{MHz}, \mathrm{C}_{2} \mathrm{D}_{2} \mathrm{Cl}_{2}, 80{ }^{\circ} \mathrm{C}\right): \delta=8.08-7.72(\mathrm{~m}$, $4 \mathrm{H}), 7.59-6.89(\mathrm{~m}, 12 \mathrm{H}), 4.05-3.69(\mathrm{~m}, 4 \mathrm{H}), 1.66-0.57(\mathrm{~m}, 30 \mathrm{H})$ ppm. ${ }^{13} \mathrm{C}$ NMR (100 MHz, $\left.\mathrm{C}_{2} \mathrm{D}_{2} \mathrm{Cl}_{2}, 80{ }^{\circ} \mathrm{C}\right): 155.5,151.7,144.2$, 136.6, 136.4, 136.3, 134.0, 12.6, 129.6, 129.3, 129.2, 126.6, 126.0, $125.0,124.5,124.4,124.2,124.0,121.0,120.6,117.1,99.9,70.2$, $31.9,29.7,29.3,29.3,25.9,22.8,14.2 \mathrm{ppm}$.

Poly[6,6'-(2,2'-dioctylbenzyloxy)binaphthyl]-alt-2,5-bithienylene [OPh$B N p \propto 2]$. Following the general procedure $(R)-6,6^{\prime}$-dibromo-2, $2^{\prime}-$ bis(4-octylbenzyloxy)-1,1'-binaphthyl (2) (60 mg, $0.071 \mathrm{mmol}$ ), 5,5"-bis(trimethylstannyl)-2.2':5,2" -terthiophene (59 mg, 0.071 $\mathrm{mmol}), \mathrm{PdCl}_{2} \mathrm{dppf}(5 \mathrm{mg}, 0.007 \mathrm{mmol})$, and $\mathrm{KF}(70 \mathrm{mg}, 0.707$ mmol) were reacted. Yield: $56 \%$. GPC (vs polystyrene standards in THF): $M_{\mathrm{n}}=3450, M_{\mathrm{w}} / M_{\mathrm{n}}=2.4 .{ }^{1} \mathrm{H}$ NMR $\left(400 \mathrm{MHz}, \mathrm{C}_{2} \mathrm{D}_{2} \mathrm{Cl}_{2}\right.$, 
Table 1. Mean Number-Average Molecular Weight $\left(M_{\mathrm{n}}\right)$, Weight-Average Molecular Weight $\left(M_{\mathrm{w}}\right)$, the Polydispersity (PD), and Degree of Polymerization (DP) of the Binaphthyl-Oligothiophene Copolymers

\begin{tabular}{|c|c|c|c|c|}
\hline polymer & $M_{\mathrm{n}}$ & $M_{\mathrm{w}}$ & PD & $\mathrm{DP}^{a}$ \\
\hline $\mathrm{BNp} \alpha 2$ & 4900 & 8200 & 1.7 & 12 \\
\hline BNp $\alpha 3$ & 2800 & 7900 & 2.9 & 10 \\
\hline OPhBNp $\alpha 2$ & 6900 & 9900 & 1.4 & 12 \\
\hline OPhBNp $\alpha 3$ & 8900 & 13400 & 1.5 & 15 \\
\hline
\end{tabular}

${ }^{a}$ Based on $M_{\mathrm{w}}$.

$\left.80{ }^{\circ} \mathrm{C}\right): \delta=8.16-7.74(\mathrm{~m}, 4 \mathrm{H}), 7.60-6.58(\mathrm{~m}, 18 \mathrm{H}), 5.13-4.74$ $(\mathrm{m}, 4 \mathrm{H}), 2.58-2.27(\mathrm{~m}, 4 \mathrm{H}), 1.62-0.65(\mathrm{~m}, 30 \mathrm{H}) \mathrm{ppm} .{ }^{13} \mathrm{C} \mathrm{NMR}$ $\left(100 \mathrm{MHz}, \mathrm{C}_{2} \mathrm{D}_{2} \mathrm{Cl}_{2}, 80{ }^{\circ} \mathrm{C}\right): 155.2,143.8,142.5,136.9,134.8$, 134.0, 130.0, 129.8, 129.2, 128.4, 128.1, 127.2, 126.7, 126.0, 124.9, $124.8,124.4,124.1,121.4,120.6,117.7,99.9,72.0,35.8,32.1$, 31.4, 29.7, 29.6, 29.4, 22.8, $14.3 \mathrm{ppm}$.

Poly[6,6'-(2,2'-dioctylbenzyloxy)binaphthyl]-alt-2,5-terthienylene $[O P h B N p \alpha 3]$. Following the general procedure $(R)-6,6^{\prime}$-dibromo2,2'-bis(4-octylbenzyloxy)-1,1'-binaphthyl (2) (60 mg, $0.071 \mathrm{mmol}$ ),

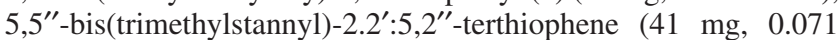
mmol), $\mathrm{PdCl}_{2} \mathrm{dppf}(5 \mathrm{mg}, 0.007 \mathrm{mmol}$ ), and $\mathrm{KF}$ (70 mg, 0.707 mmol) were reacted. Yield: $54 \%$. GPC (vs polystyrene standards in THF): $M_{\mathrm{n}}=3450, M_{\mathrm{w}} / M_{\mathrm{n}}=2.4 .{ }^{1} \mathrm{H} \mathrm{NMR}\left(400 \mathrm{MHz}, \mathrm{C}_{2} \mathrm{D}_{2} \mathrm{Cl}_{2}\right.$, $\left.80{ }^{\circ} \mathrm{C}\right): \delta=8.10-7.76(\mathrm{~m}, 4 \mathrm{H}), 7.58-6.63(\mathrm{~m}, 20 \mathrm{H}), 5.11-4.71$ $(\mathrm{m}, 4 \mathrm{H}), 2.60-2.25(\mathrm{~m}, 4 \mathrm{H}), 1.66-0.60(\mathrm{~m}, 30 \mathrm{H}) \mathrm{ppm} .{ }^{13} \mathrm{C} \mathrm{NMR}$ $\left(100 \mathrm{MHz}, \mathrm{C}_{2} \mathrm{D}_{2} \mathrm{Cl}_{2}, 80{ }^{\circ} \mathrm{C}\right): 155.2,144.1,142.5,136.7,136.5$, 134.8, 134.0, 130.0, 129.8, 129.7, 129.2, 128.4, 127.2, 127.0, 126.7, 126.0, 125.1, 124.9, 124.8, 124.6, 124.5, 124.2, 121.4, 120.6, 117.7, 99.9, 71.7, 35.9, 32.2, 31.7, 29.74, 29.71, 29.5, 23.0, 14.5 ppm.

Table 1 summarizes the molecular weight data of the copolymers including the mean number-average molecular weight $\left(M_{\mathrm{n}}\right)$, the weight-average molecular weight $\left(M_{\mathrm{w}}\right)$, the polydispersity $(\mathrm{PD}=$ $M_{\mathrm{w}} / M_{\mathrm{n}}$ ), and the degree of polymerization (number of binaphthyloligothiophene repeat units, DP).

The structures and acronyms of the four copolymers studied are given in Scheme 2. The mean number-average molecular weights $M_{\mathrm{n}}$ were in the range $M_{\mathrm{n}}=2800-8900 \mathrm{~g} \mathrm{~mol}^{-1}$ with polydispersities between 1.4 and 2.9 (see Table 1). On the basis of the $M_{\mathrm{w}}$ data, we obtained degrees of polymerization between 10 [BNpa3] and 15 [OPhBNpa3] (see Table 1).

Equipment and Methods. Absorption and fluorescence spectra were recorded on Shimadzu UV-2100 and Horiba-Jobin-Ivon SPEX Fluorog 3-22 spectrometers, respectively. The fluorescence spectra were corrected for the wavelength response of the system.

The fluorescence quantum yields were measured using quinquethiophene $\left(\phi_{\mathrm{F}}=0.33 \text { in } \mathrm{MCH}\right)^{27}$ as standard.

The fluorescence anisotropy $r$ was measured using GlanThompson polarizers for recording the fluorescence spectra with vertical-vertical $I_{\mathrm{vv}}$ and vertical-horizontal $I_{\mathrm{vh}}$ orientation of the excitation and emission polarizers. The $r$ values were calculated with eq $1^{28}$

$$
\langle r\rangle=\frac{I_{\mathrm{vv}}-G I_{\mathrm{vh}}}{I_{\mathrm{vv}}+2 G I_{\mathrm{vh}}}
$$

where the grating factor $G$ is $G=I_{\mathrm{hv}} / I_{\mathrm{hh}}$.

Fluorescence decays with nanosecond time resolution were measured using a home-built TCSPC apparatus described elsewhere ${ }^{29}$ and were analyzed using the modulating functions method of Striker. ${ }^{30}$ Fluorescence decay times with picosecond time resolution were obtained both by using a previously described system $^{31}$ or by using a home-built picosecond time correlated single photon counting (TCSPC) apparatus. The excitation source consists of a picosecond Spectra Physics mode-lock Tsunami laser (Ti: sapphire) model 3950 (repetition rate of about $82 \mathrm{MHz}$, tuning range $700-1000 \mathrm{~nm}$ ), pumped by a Millennia Pro-10s, frequency-doubled continuous wave $(\mathrm{CW})$, diode-pumped, solid-state laser $\left(\lambda_{\mathrm{em}}=532\right.$ $\mathrm{nm})$. A harmonic generator model GWU-23PS (Spectra-Physics) is used to produce the second and third harmonic from the Ti:sapphire laser exciting beam frequency output. The samples where measured with excitation at $395 \mathrm{~nm}$ and the horizontally polarized output beam from the GWU (second harmonic) was first passed through a ThorLabs depolarizer (WDPOL-A) and after by a Glan-Thompson polarizer (Newport 10GT04) with vertical polarization. Emission at $90^{\circ}$ geometry collected at magic angle polarization was detected through a double subtractive Oriel Cornerstone 260 monochromator by a Hamamatsu microchannel plate photomultiplier (R3809U-50). Signal acquisition and data processing was performed employing a Becker \& Hickl SPC-630 TCSPC module. Fluorescence decays and the instrumental response function (IRF) where collected using 4096 channels in a 0.814 ps/ channel scale, until $5 \times 10^{3}$ counts at maximum were reached. The full width at half-maximum (fwhw) of the IRF was about 22 ps and was highly reproducible with identical system parameters.

The experimental setup (Applied Photophysics laser flash photolysis apparatus pumped by a Spectra-Physics Nd:YAG laser) used to obtain triplet spectra and triplet yields has been described elsewhere. ${ }^{29,32}$ Triplet state absorption spectra were also characterized by pulse radiolysis (using the Free Radical Research Facility, Daresbury, UK) as has been described in detail elsewhere. ${ }^{10}$ Spectra are comparable with those obtained by laser flash photolysis, except at longer wavelengths $(>700 \mathrm{~nm})$, where those obtained by flash photolysis appear to be attenuated by the diminished response of the detector. First-order kinetics were observed in all cases for the decay of the lowest triplet state, and lifetime values were in the microsecond range.

Special care was taken in determining triplet yields to have optically matched dilute solutions $(\mathrm{abs} \approx 0.2$ in a $10 \mathrm{~mm}$ square cell) and low laser energy $(\leq 2 \mathrm{~mJ})$ to avoid multiphoton and $\mathrm{T}-\mathrm{T}$ annihilation effects.

The triplet molar absorption coefficients were obtained by the singlet depletion and energy transfer methods. Details on the experimental procedures and data analysis used can be found in refs 29 and 32.

Room-temperature singlet oxygen phosphorescence was detected at $1270 \mathrm{~nm}$ with equipment and procedures elsewhere reported. ${ }^{29,32}$ From these signals the singlet oxygen quantum yields were obtained.

Thin films from the compounds were obtained with a desktop precision spin-coating system, model P6700 series from Speedline Technologies. Solid-state thin film from the samples were obtained by deposition of a few drops from a solution of the compounds into a circular sapphire substrate $(10 \mathrm{~mm}$ diameter $)$ followed by spin-coating $(2500 \mathrm{rpm})$ in a nitrogen-saturated atmosphere (2 psi). The solutions for spin-coating were prepared by adding $2 \mathrm{mg}$ of the samples to $15 \mathrm{mg}$ of Zeonex in $200 \mu \mathrm{L}$ of toluene solution with stirring at $40{ }^{\circ} \mathrm{C}$ for $30 \mathrm{~min}$. The fluorescence emission spectra of the thin films were obtained with a Horiba-Jobin-Yvon integrating sphere. The solid-state photoluminescence quantum yields in thin films were obtained as previously described. ${ }^{29,32}$

Molecular orbital calculations were carried out with Hyperchem 7.0 program, using AM1 for geometry optimization and AM1-CI, PM3-CI, and ZINDO/S-CI (129 CIs) for the calculation of the electronic states energy. ${ }^{33}$

Scheme 3 shows examples of optimized conformations of $\mathrm{BNp} \alpha 2$ and $\mathrm{BNp} \alpha 3$. In all cases, the dihedral angle between the naphthyl groups was close to $90^{\circ}$, which, if correct, implies that the binaphthyl units act as efficient conjugation barriers. This gains particular relevance for the investigation of the relative contribution of conformational relaxation vs energy migration (transfer) within the copolymers chains.

\section{Results and Discussion}

Synthesis of the Polymers. The synthesis of the oligothiophene monomers has been described elsewhere. ${ }^{34}$ The chemical structures of the desired binaphthyl-oligothiophene copolymers and the synthetic protocols are schematically depicted in Scheme 1. The binaphthyl monomers were prepared from the respective diols by alkylation with 1-bromooctane or 1-(bromomethyl)-4octylbenzene using anhydrous potassium carbonate as base in acetonitrile to give 6,6'-dibromo-2,2'-bis(octyloxy)-1,1'-binaph- 
Scheme 1. Preparative Procedure toward Binaphthyl-Oligothiophene Copolymers $X ; n=2,3$

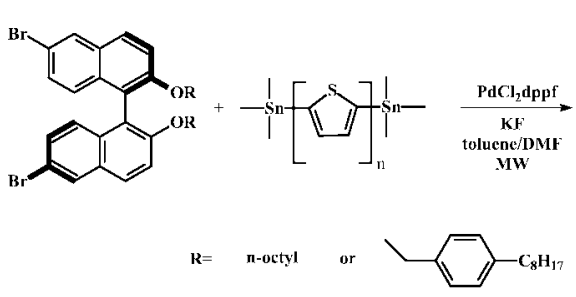

(1)

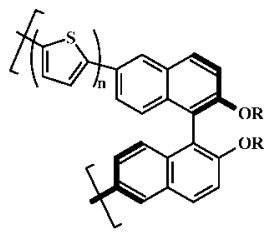

Scheme 2. Structures and Acronyms of the Binaphthyl-Oligothiophene Copolymers Investigated

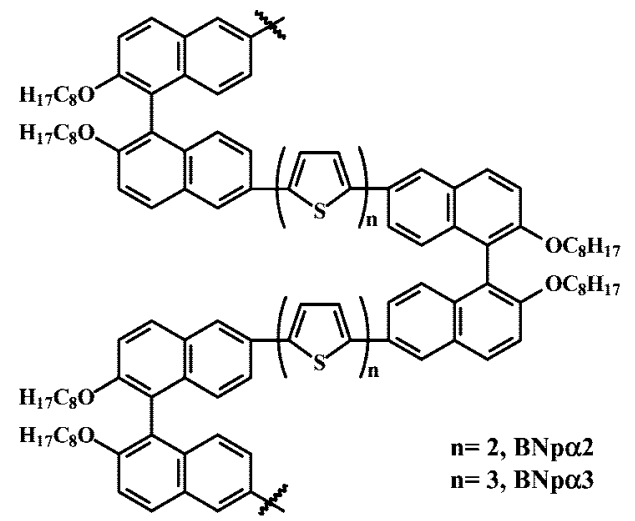

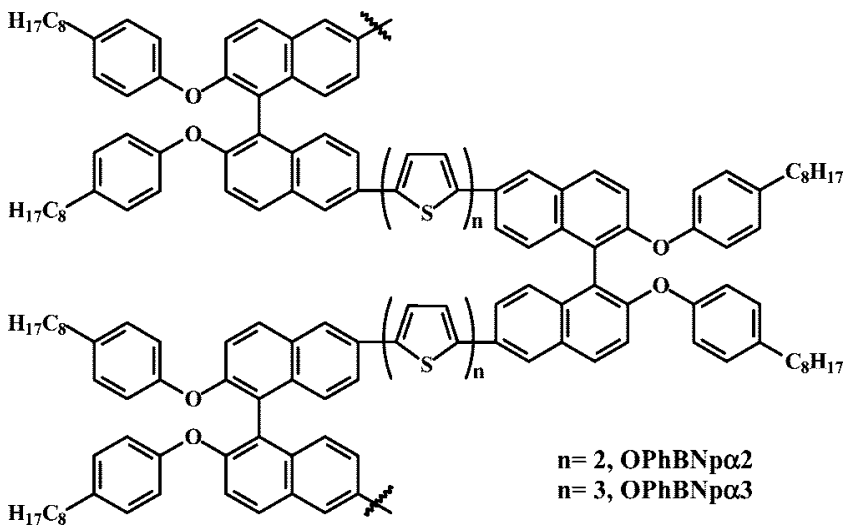

thyl (1) and 6,6'-dibromo-2,2'-bis(4-octylbenzyloxy)-1,1'-binaphthyl (2). The alternating copolymers were prepared via a microwave assisted Stille-type cross-coupling protocol. ${ }^{35,36}$

Absorption and Fluorescence. The absorption spectra for the copolymers at room temperature ( $293 \mathrm{~K})$, low temperature ( $77 \mathrm{~K}$, given by the fluorescence excitation spectra), and in the solid state (thin films) are broad and devoid of vibrational structure (Figure 1). It is worth noting that the absorption band due to the $\left(1,1^{\prime}\right.$-bi)naphthyl chromophore, BNp (Figure 2), is not observed in the copolymers, indicating that part of this moiety is in conjugation with the oligothiophene units of the backbone.

A red shift of ca. $\sim 20 \mathrm{~nm}$ in the absorption maximum was observed with the increase of size of the oligothiophene group (see Table 2). The calculated values for the lowest electronic transitions of the parent compounds of $\mathrm{BNp} \alpha 2$ and $\mathrm{BNp} \alpha 3$ (Scheme 3) are $457 \mathrm{~nm}$ (AM1) and $512 \mathrm{~nm}$ (ZINDO/S), in agreement with the experimental values (see Table 2), which gives support to the calculated molecular geometries.

Upon going from the spectra in solution at $293 \mathrm{~K}$ to those in glasses at $77 \mathrm{~K}$, the absorption bands were red-shifted (with a

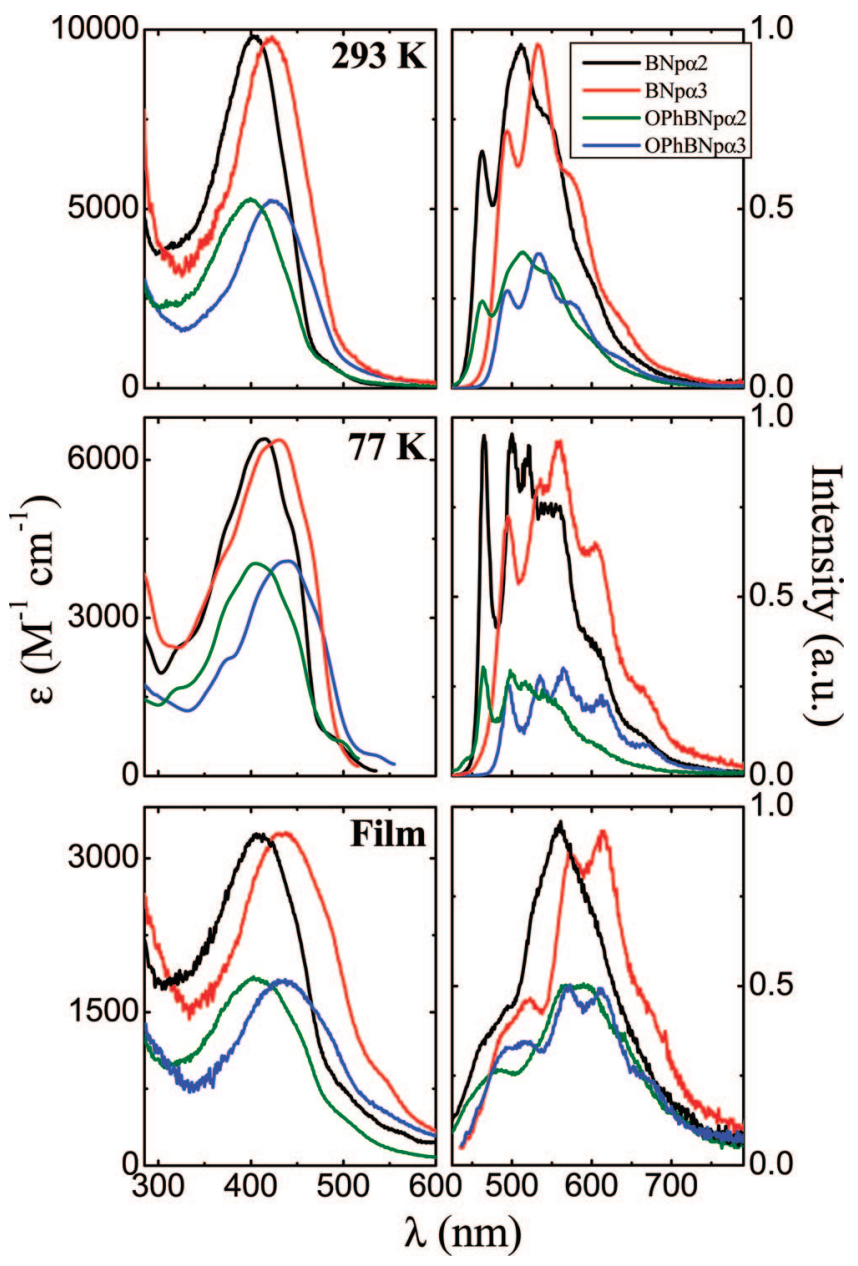

Figure 1. Absorption and emission (fluorescence) spectra for the binaphthyl-oligothiophenes copolymers in toluene at room temperature $(293 \mathrm{~K})$, low temperature $(77 \mathrm{~K})$, and in the solid state (thin films).

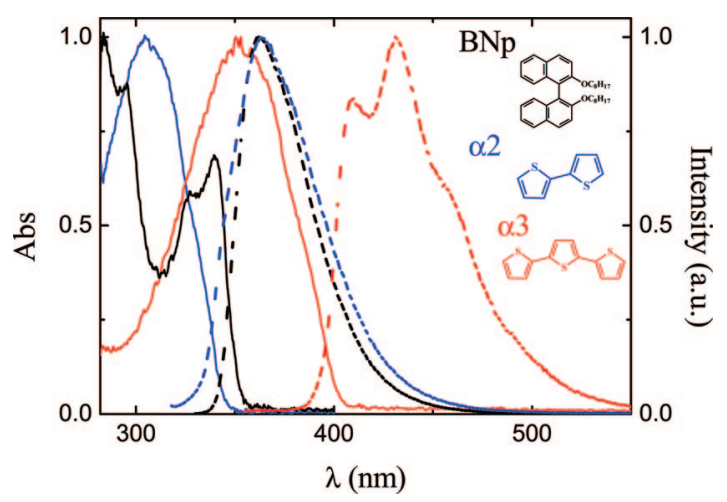

Figure 2. Normalized absorption and fluorescence emission spectra of the constitutional chromophoric units of the binaphthyl-oligothiophenes copolymers: 2,2'-octyloxy-1,1'-binaphthyl (BNp), bithiophene $(\alpha 2)$, and terthiophene $(\alpha 3)$ in toluene solution at room temperature $(293 \mathrm{~K})$.

minimum of $\sim 8 \mathrm{~nm}$ in $\mathrm{BNp} \alpha 3$ and a maximum of $17 \mathrm{~nm}$ in OPhBNpa3; see Table 2). Analogous behavior was observed at $293 \mathrm{~K}$ on going from solution to the solid-state films.

Figure 1 also presents the fluorescence emission spectra for the copolymers at 293 and $77 \mathrm{~K}$ and in thin films. A small red shift $(1-3 \mathrm{~nm})$ of the $0-0$ vibronic is observed upon cooling from RT to LT (see Table 2).

In contrast to the absorption spectra, the RT fluorescence emission spectra show vibrational structure. Again, there is no evidence for (1,1'-bi)naphthyl-related emission bands, supporting the idea that $\pi$-electron delocalization involves both the (bi)- 
Table 2. Spectroscopic Parameters for the Binaphthyl-Oligothiophenes Copolymers in Toluene at Room Temperature (293 K), Low Temperature (77 K), and in Thin Films

\begin{tabular}{|c|c|c|c|c|c|c|c|c|}
\hline polymer & $\lambda_{\max }^{\mathrm{Abs}}(\mathrm{nm}) 293 \mathrm{~K}$ & $\lambda_{\max }^{\mathrm{Abs}}(\mathrm{nm}) 77 \mathrm{~K}$ & $\lambda_{\max }^{\mathrm{Abs}}(\mathrm{nm})$ film & $\lambda_{\max }^{\text {Fluo }}(\mathrm{nm})^{a} 293 \mathrm{~K}$ & $\lambda_{\max }^{\text {Fluo }}(\mathrm{nm})^{a} 77 \mathrm{~K}$ & $\lambda_{\max }^{\text {Fluo }}(\mathrm{nm})^{a}$ film & $\lambda_{\max }^{\mathrm{T}_{1} \rightarrow \mathrm{T}_{n}}(\mathrm{~nm})$ & $\varepsilon_{\mathrm{TT}}\left(\mathrm{M}^{-1} \mathrm{~cm}^{-1}\right)$ \\
\hline $\mathrm{BNp} \alpha 2$ & 404 & 415 & 410 & $462,511,545$ & $465,500,521$ & 495,560 & 660 & 41510 \\
\hline $\mathrm{BNp} \alpha 3$ & 422 & 430 & 435 & $494,534,573$ & $495,535,558$ & $520,570,615$ & 680 & 25000 \\
\hline OPhBNp $\alpha 2$ & 400 & 410 & 405 & $462,513,545$ & $464,500,516$ & 480,580 & 660 & 28810 \\
\hline
\end{tabular}

$a$ The italic wavelength is the band maximum.

Scheme 3. Optimized Conformations Obtained with the AM1 and ZINDO/S-CI Methods for the Structures of (A) BNp 2 and (B) BNp $\alpha 3$

(A)

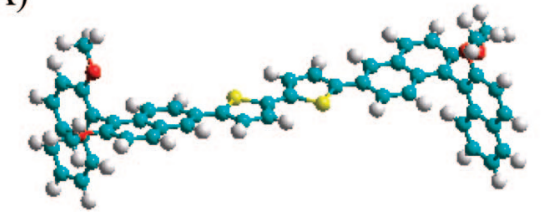

(B)

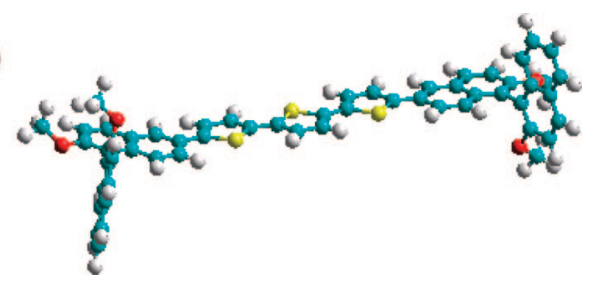

Table 3. Photophysical Properties for the Binaphthyl-Oligothiophenes Copolymers in Toluene (and Methylcyclohexane) at Room Temperature (293 K) and Low Temperature ( $77 \mathrm{~K})$ and in the Solid State

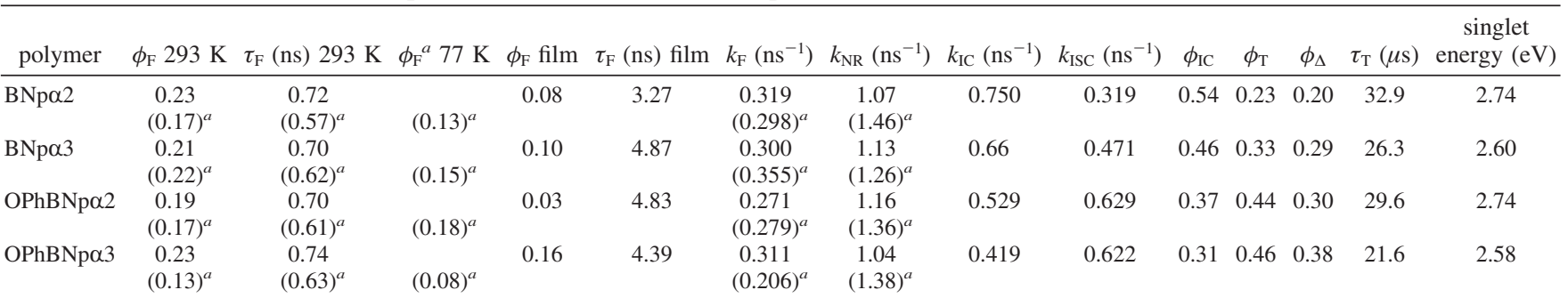

${ }^{a}$ In parentheses, values in methylcyclohexane.

naphthyl and the oligothiophene moieties (Figure 1). Moreover, and in contrast with the absence of any significant shift of the $0-0$ vibronic, there is a significant change in the progression of the remaining vibronic bands at $77 \mathrm{~K}$ relative to $293 \mathrm{~K}$. In view of the Franck-Condon forbidden nature of the first absorption band of these compounds and of the highly resolved nature of the emission band (at both 293 and $77 \mathrm{~K}$ ) there is clearly a change in the potential energy curves related to the ground and first excited singlet states. ${ }^{37}$ In the case of the oligothiophenes $^{27}$ (and naphthalene-oligothiophenes ${ }^{33}$ ), this has been attributed to the existence of an ensemble of different conformations in the ground state and to a planar quinoidallike structure ${ }^{38}$ in $S_{1}$. This more rigid, quinoidal-like structure in thiophene-like oligomers and polymers promotes a good resolution of the vibronic energetic levels, which is consistent with the observed well-resolved fluorescence spectra observed under all conditions. While detailed assignment of the vibronic modes involved is outside the scope of this study, it is clear by comparison of the fluorescence spectra of the binaphthyl-oligothiophenes copolymers in Figure 1 with those of the model thiophene oligomers (bithiophene and terthiophene) in Figure 2 that for the terthiophene copolymer derivatives (Bnp $\alpha 3$ and $\mathrm{OPhBNp}$ (3) the emission spectra present a similar (although red-shifted) vibrational progression to the analogous $\alpha 3$ oligomer. However, the same is not observed with the terthiophene copolymer derivatives where, in contrast to the bithiophene and 2,2'-octyloxy-1,1'-binaphthyl (BNp) oligomers (Figure 2), the emission band is vibronically resolved (Figure 1). In contrast, the spectra of the Bnpo 2 and $\mathrm{OPhBNp} \alpha 2$ derivatives are devoid of vibronic resolution, which is similar to what is found with the naphthalene-oligothiophene counterparts where the fluorescence is also poorly resolved at $\mathrm{RT} .{ }^{33}$ This seems to suggest that with the terthiophene copolymers the exciton is more localized (with a structure close to that found for the naphthalene-oligothiophene counterparts ${ }^{33}$ ), on the contrary to what is observed for the bithiophene copolymers that should adopt a structure similar to that found for the mononaphthalene derivatives, the poly[2,6-(1,5-dioctylnaphthalene)] thiophenes. ${ }^{11}$

The dependence of the photophysical properties has also been seen with thiophene polymers and copolymers and is found to be strongly influenced by the substitution, degree of backbone torsion, media, etc. ${ }^{11,21,39,40}$

With our copolymers, a narrowing of the vibronic bands of the emission spectrum is observed upon going to low-temperature glasses. This is likely to be a consequence of a reduction of the degree of conformational freedom of the polymers.

The absorption and emission spectra for the binaphthyl building block of the copolymers (2,2'-octyloxy-1,1'-binaphthyl$\mathrm{BNp}$; Figure 2, structure as inset) in methylcyclohexane solution display much shorter absorption and emission wavelength maxima than any of the copolymers investigated (Table 2). Moreover the fluorescence quantum yield $\left(\phi_{\mathrm{F}}=0.60\right)$ and lifetime $\left(\tau_{\mathrm{F}}=6.52 \mathrm{~ns}\right)$ are also much greater than any of the values found for the polymers studied (see Table 3 ).

In the solid state (thin films) a loss of vibronic structure is seen with the concomitant broadening and red shift of the emission spectra. These results provide strong evidence for aggregation in the solid state. The broadening and loss of structure of the emission spectra in the solid state are generally attributed to intermolecular interactions giving rise to different types of packing between the polymer chains and different degrees of twisting in the polymer/oligomer backbone, leading to broad and unstructured emission bands. Moreover, the evidence for aggregates in thin films comes from the absorption spectra which show an increased absorbance at the longer wavelength region as compared to those in their corresponding solution states at $293 \mathrm{~K}$ (see Figure 1).

It is also interesting to observe the fluorescence excitation spectra obtained at 293 and $77 \mathrm{~K}$ and collected in different regions of the emission spectra, depicted in Figure 3 for $\mathrm{BNp} \alpha 3$. 


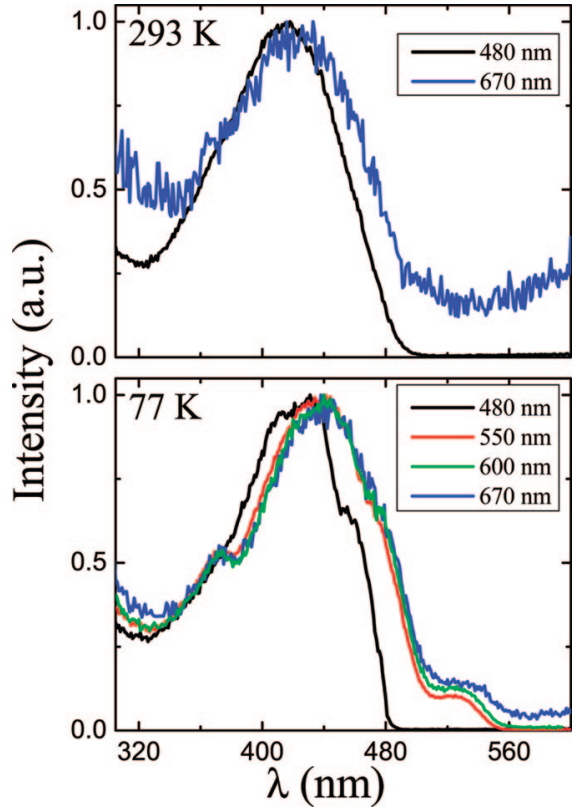

Figure 3. Fluorescence excitation spectra for BNp $\alpha 3$ in toluene at 293 and $77 \mathrm{~K}$ collected at different emission wavelengths.

Table 4. Fluorescence Decay Times $\left(\tau_{i}\right)$ and Preexponential Factors $\left(a_{i j}\right)$ for the Copolymers in Toluene at $293 \mathrm{~K}$ and with $\lambda_{\mathrm{exc}}=380 \mathrm{~nm}^{a}$

\begin{tabular}{|c|c|c|c|c|c|c|c|c|}
\hline polymer & $\lambda_{\mathrm{em}}$ & $\tau_{1}(\mathrm{ps})$ & $\tau_{2}(\mathrm{ps})$ & $\tau_{3}(\mathrm{ps})$ & $a_{i 1}$ & $a_{i 2}$ & $a_{i 3}$ & $\chi^{2}$ \\
\hline \multirow[t]{3}{*}{$\mathrm{BNp} \alpha 2$} & 460 & 60 & 420 & 720 & 0.38 & 0.54 & 0.08 & 1.27 \\
\hline & 510 & & & & 0.23 & 0.52 & 0.25 & 1.24 \\
\hline & 670 & & & & -0.18 & 0.16 & 0.84 & 1.34 \\
\hline \multirow[t]{3}{*}{$\mathrm{BNp} \alpha 3$} & 495 & 49 & 434 & 700 & 0.21 & 0.51 & 0.28 & 1.18 \\
\hline & 530 & & & & 0.14 & 0.49 & 0.37 & 0.98 \\
\hline & 650 & & & & -0.20 & 0.29 & 0.71 & 1.13 \\
\hline \multirow[t]{3}{*}{$\mathrm{OPhBNp} \alpha 2$} & 460 & 40 & 390 & 700 & 0.31 & 0.51 & 0.18 & 1.14 \\
\hline & 510 & & & & 0.17 & 0.45 & 0.38 & 0.93 \\
\hline & 670 & & & & -0.20 & 0.12 & 0.88 & 1.04 \\
\hline \multirow[t]{3}{*}{$\mathrm{OPhBNp} \alpha 3$} & 495 & 51 & 477 & 740 & 0.25 & 0.58 & 0.17 & 1.17 \\
\hline & 530 & & & & 0.16 & 0.58 & 0.28 & 1.01 \\
\hline & 650 & & & & -0.19 & 0.42 & 0.58 & 1.05 \\
\hline
\end{tabular}

${ }^{a}$ The data presented were obtained by global analysis of the decays. Also presented are the chi-squared values for a better judgment of the quality of the fits.

A red shift in the wavelength maxima and the appearance of a new band at longer wavelengths are visible upon the increment of the emission wavelength. At low temperature, by collecting the emission at longer wavelengths, there is clear evidence for two distinct bands with maxima at $\sim 440$ and $523 \mathrm{~nm}$ (Figure 3). This points out to the existence of different segments (chromophoric units) within the polymer with different absorptions. While the assignment of this long wavelength absorption (around $520 \mathrm{~nm}$ ) is not yet completely clear, we feel that it is unlikely to be due to either impurities or aggregation. The binaphthyl unit is expected to act as a conjugation barrier. However, the longer wavelength band at low temperatures may reflect some of the polymers having longer range conjugation, possibly due to this unit not completely blocking conjugation.

Time-Resolved Fluorescence. Fluorescence lifetimes $\left(\tau_{\mathrm{F}}\right)$ were obtained in solution (with picosecond time resolution) and in the solid state (with nanosecond time resolution) (see Tables 3 and 4). The lifetimes in films (Table 3) are about 6-fold longer than those in room temperature solution and are of a similar order of magnitude to the radiative lifetimes calculated from room temperature fluorescence quantum yields and lifetimes $\left(1 / k_{\mathrm{F}}\right)$. In contrast, the fluorescence quantum yields in films and in low temperature glasses are, in general, lower than in solution

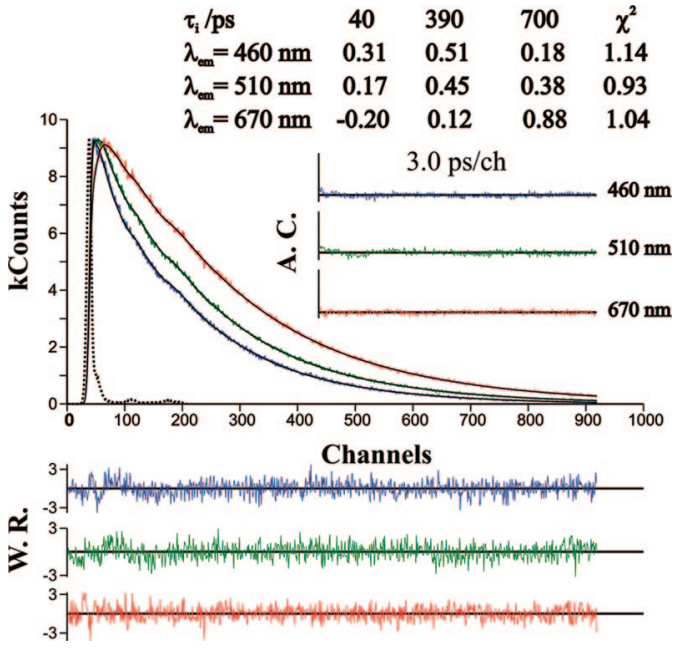

Figure 4. Fluorescence decays for $\mathrm{OPhBNp} \alpha 2$ in toluene at $T=293$ $\mathrm{K}$. For a better judgment of the quality of the fits, autocorrelation functions (A.C.), weighted residuals (W.R.), and chi-square values $\left(\chi^{2}\right)$ are also presented as insets. The dashed lines in the decays are the pulse instrumental response.

at room temperature (Table 3). This strongly suggests that the nonradiative deactivation pathways present different contribution in solution and the solid state, most probably resulting from intrachain processes in isolated molecules in solution and interchain interactions (or interactions with the matrix) in the solid state.

The fluorescence lifetimes in toluene solution presented in Table 3 are similar to the major decay components obtained with picosecond time resolution. The fluorescence decay times in solution were also collected as a function of the emission wavelength (Table 4 and Figure 4). In general, the fluorescence decay times do not show any significant change across the fluorescence spectra and can be considered to be independent of the emission wavelength $\left(\lambda_{\mathrm{em}}\right)$ over the whole range studied. However, the same is not true with the pre-exponential factors $\left(a_{i j}\right)$. This allows the global analysis of the temporal profiles of fluorescence decays. As can be seen from Table 4 and Figure 4 , the fluorescence decays for the polymers studied are best fitted with triple-exponential decay laws according to the equation

$$
I_{\lambda}(t)=a_{i 1} \mathrm{e}^{-t / \tau_{1}}+a_{i 2} \mathrm{e}^{-t / \tau_{2}}+a_{i 3} \mathrm{e}^{-t / \tau_{3}}
$$

where $a_{i j}(j=1,2,3)$ are the pre-exponential factors and $\tau_{i}$ are the decays times (with $i=1$ for $\lambda_{\mathrm{em}}=460 \mathrm{~nm}, i=2$ for $\lambda_{\mathrm{em}}=$ $510 \mathrm{~nm}$, and $i=3$ for $\lambda_{\mathrm{em}}=670 \mathrm{~nm}$ for $\mathrm{BNp} \alpha 2$ ). In Table 4 , the shortest lifetime component appears as a decay time at short wavelengths and as a risetime at longer wavelengths.

There is an ongoing controversy on the exact meaning of the fast (few picoseconds) components in $\pi$-conjugated polymers fluorescence decays. These have been attributed to fast relaxation processes within the polymer backbone including both excitation energy migration in the polymer to the lowest energy conjugation segment ${ }^{17}$ and torsional motions leading to conformational reorganization of the excited state. ${ }^{19,41}$ While in general the dominant mechanism for the fast decay has been attributed to energy transfer along the chain, ${ }^{17,42-45}$ it has been pointed out that conformational relaxation is a general phenomenon occurring in nonrigid polymers and oligomers, which much coexist with other eventual processes such energy transfer. ${ }^{19,20}$ Further, the coexistence of these two processes has also been proposed. ${ }^{46}$

With the present data and for the polymers studied here, differentiation between the two mechanisms is, a priori, uncertain, and thus the nature of the shortest decay component 


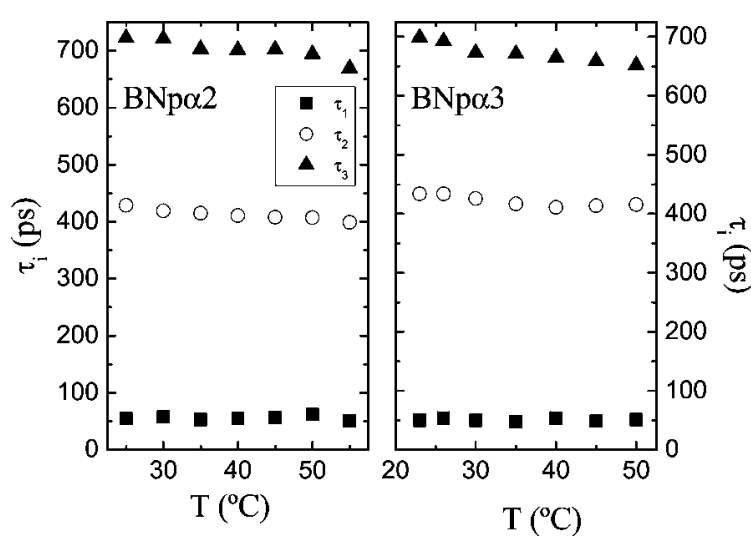

Figure 5. Fluorescence decay times $\left(\tau_{i}\right)$ dependence with temperature for $\mathrm{BNp} \alpha 2$ and $\mathrm{BNp} \alpha 3$ in toluene.

can be associated with conformational relaxation and/or energy migration. Additional information is however available from the temperature dependence of the decay times shown in Figure 5. Upon increasing temperature, the shortest decay time remains constant within experimental error. Because conformational relaxation strongly depends on temperature and solvent viscosity, ${ }^{19,41}$ we conclude that it is not responsible for the shortest decay component. The absence of detectable relaxation results from the absence of side chains in the naphthyl-oligothiophenenaphthyl chromophoric unit, capable of slowing down the otherwise very fast torsions of the chain at normal viscosities (e.g., toluene). The torsional time has been empirically found to be linearly dependent on the side-chain volume. ${ }^{41}$ Extrapolation of this correlation to the van der Waals volume of the hydrogen atom predicts a relaxation time in the subpicosecond time range. Accordingly, dithiophene and terthiophene and other thiophene oligomers do not show detectable conformational relaxation in the picoseconds time range. $27,47,48$

The alternative assignment of the fast decay component to energy transfer is not trivial because all segments have the same length and the spectral overlap is small. However, it may occur with slower rate, and also, it is likely that the Dexter exchange mechanism will contribute. ${ }^{49,50}$ This would lead to relatively long times for energy transfer, as observed.

The longest decay time is attributed to the emission of the relaxed species of the polymer, and its contribution increases with the emission wavelength, showing that the emission from the relaxed species is dominant at lower energies. The additional middle decay time $(\sim 390-480$ ps $)$ could be related to the emission of an ensemble of conformers with shorter conjugation length (within the polymer) that predominantly emit at shorter wavelengths as seen by the pre-exponential factors and as will be discussed below.

Since there is strong decoupling between the oligothiophene and naphthalene chromophores, it is likely that the relaxed excited species would partially reflect this geometry and would therefore be similar to that present in Scheme 3 .

It is again fruitful to compare the decay times of the copolymers studied with the more simple analogues of 1-naphthyl(oligo)thiophenes with two $[\operatorname{Naph}(\alpha 2)]$ and three $[\operatorname{Naph}(\alpha 3)]$ thiophene units. $^{33}$ As reported elsewhere, the fluorescence lifetimes of these are 360 and 470 ps, respectively. ${ }^{33}$ From Table 4 it can be seen that these values are close to the intermediate decay times of the binaphthyl-oligothiophene copolymers investigated. This suggests that the intermediate component could result from the emission of conformers where one of the naphthyl groups, in the naphthyl-oligothiophene-naphthyl, is twisted (and hence loses conjugation). Given the nature of the binaphthyl link to the polymer chain, planarization could be too slow to allow the relaxation to the full planar chromophore

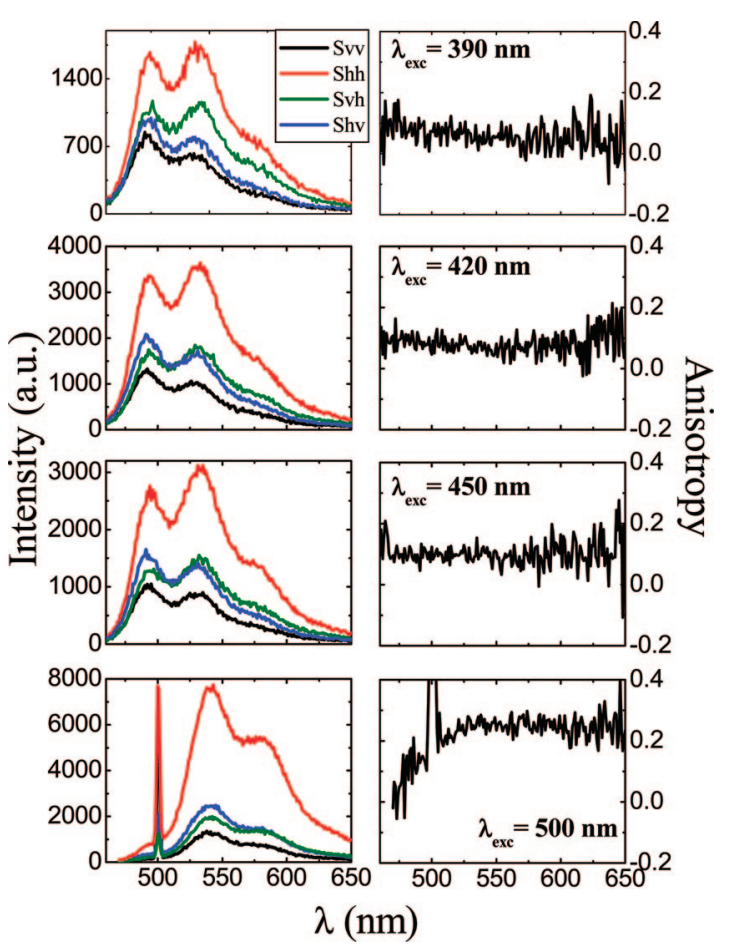

Figure 6. Polarized fluorescence emission spectra and anisotropy values for $\mathrm{BNp} \alpha 3$ in toluene at $293 \mathrm{~K}$. The signal S was collected with horizontal (h) and vertical (v) orientation of the excitation (first subscript) and emission (second subscript) polarizers.

within its lifetime. In agreement with this is the observation that the emission spectra of $\operatorname{Naph}(\alpha 2)$ and $\operatorname{Naph}\left(\alpha_{3}\right)$ show residual emission above $\lambda_{\mathrm{em}}=650 \mathrm{~nm}$ and emission maxima at $\sim 450 \mathrm{~nm}[435 \mathrm{~nm}$ for $\operatorname{Naph}(\alpha 2)$ and $470 \mathrm{~nm}$ for $\operatorname{Naph}(\alpha 3)] .{ }^{33}$ With PPV oligomers and polymers, an alternative explanation has been given involving possible trans - cis photoisomerization upon excitation, with the residual emission attributed to the $c i s$ isomer. ${ }^{16,20}$ Although this hypothesis cannot be discarded with these binaphthyl- $\alpha$-thiophene copolymers, since trans and cis geometries can occur with both the bithiophene and terthiophene units, in the present case we are more in favor of the first hypothesis: isolated segments involving the conjugation of two naphthyls connected by an oligothiophene unit.

Steady-State Fluorescence Anisotropy. Additional information on the relaxation processes on these polymers can be obtained from fluorescence (excitation and emission) anisotropy measurements. For these studies, we selected BNp $\alpha 3$ as an illustrative example.

From Figure 6 it can be seen that the fluorescence anisotropy values with excitation at shorter wavelengths $(390 \mathrm{~nm})$ gradually decrease from 0.1 at $\lambda_{\mathrm{em}}=460 \mathrm{~nm}$ to 0.02 (above $\sim 575 \mathrm{~nm}$ ). This can be related to energy transfer between different chromophores. However, with excitation at $420 \mathrm{~nm}$ the anisotropy values decrease from 0.1 to 0.05 (at $\sim 620 \mathrm{~nm}$ ) and increases thereon. Excitation at longer wavelengths further increases the anisotropy values, and in the case of $\lambda_{\mathrm{exc}}=500$ $\mathrm{nm}$ the value that is reached is close to the maximum value predicted theoretically, consistent with the fact that segments absorbing at longer wavelengths suffer insignificant changes upon excitation. This is also consistent with the observation in Figure 7 where the anisotropy values in the excitation spectra increases sharply for $\lambda>500 \mathrm{~nm}$.

All of the above indicates that excitation in the tail of the absorption spectra leads to emission of more relaxed conjugation segments which cannot further depolarize (or transfer excess energy) to other segments and consequently display higher anisotropy values. 


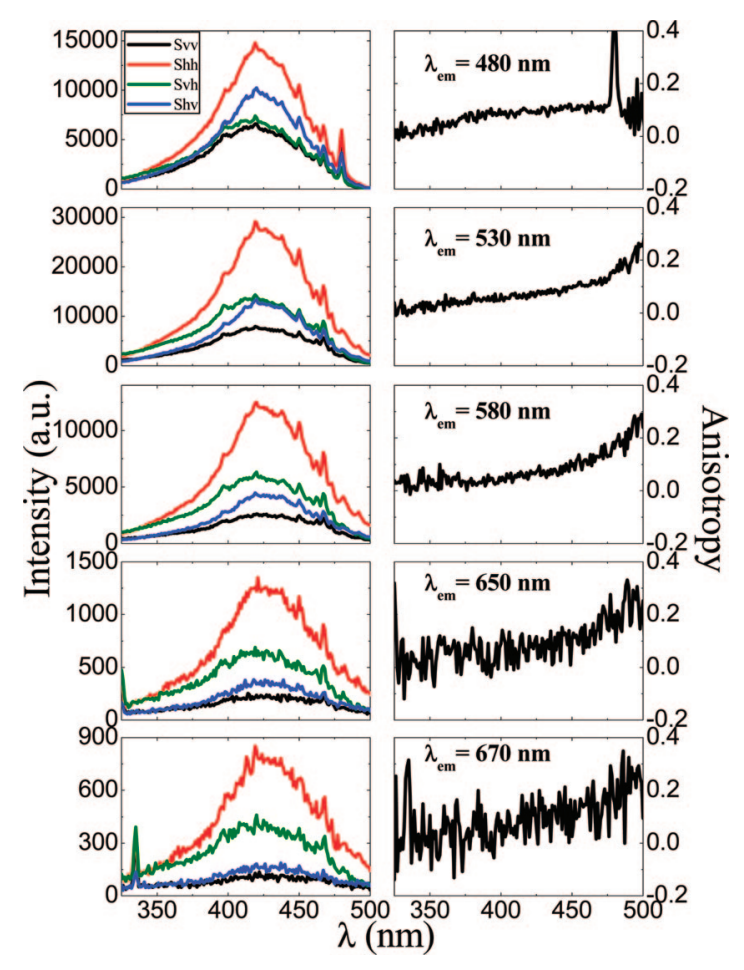

Figure 7. Polarized fluorescence excitation spectra and anisotropy values for $\mathrm{BNp} \alpha 3$ in toluene at $293 \mathrm{~K}$. The signal $\mathrm{S}$ was collected with horizontal (h) and vertical (v) orientation of the excitation (first subscript) and emission (second subscript) polarizers.

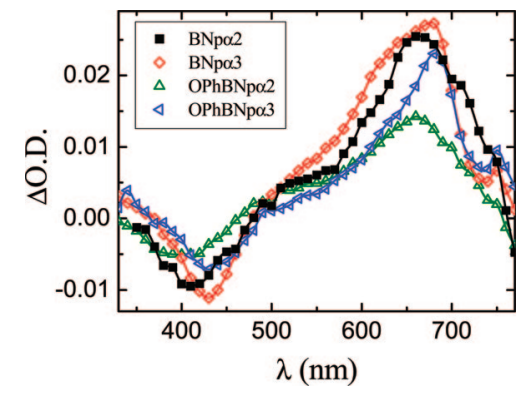

Figure 8. Transient triplet-triplet spectra of the investigated binaphthyl-oligothiophene copolymers in toluene at room temperature (293 $\mathrm{K})$.

Triplet State. Transient triplet-triplet absorption spectra were observed following laser flash photolysis at 355 and 532 $\mathrm{nm}$ of degassed solutions of the copolymers in toluene (Figure 8 ). The spectra show depletion of the ground state between 330 and $480 \mathrm{~nm}$ and an intense absorption band between 510 and $750 \mathrm{~nm}$ for all cases. The transient triplet-triplet absorption spectra of these samples are very similar to maxima in the 660-680 nm region (Figure 8 and Table 2). The spectra are broad, suggesting some delocalization of the excited triplet state due to effective conjugation along the copolymer backbone.

The spectra and triplet energies were also characterized by the pulse radiolysis energy transfer technique in benzene solution. $^{51}$ The transient absorption bands were seen to be similar to those obtained by laser flash photolysis except at longer wavelengths. In the absence of phosphorescence we have used the pulse radiolysis energy transfer method to determine the triplet energy of the copolymers. ${ }^{11}$ For all the polymers the values obtained for the triplet energies were $1.75 \pm 0.05 \mathrm{eV}$. The singlet energies (see Table 3 ) for the polymers are in the range $2.58-2.74 \mathrm{eV}$, giving an energy splitting between the lowest singlet $\left(\mathrm{S}_{1}\right)$ and triplet $\left(\mathrm{T}_{1}\right)$ lying states, $\Delta E_{\mathrm{S}_{1}-\mathrm{T}_{1}}$, roughly constant $(0.9 \pm 0.1 \mathrm{eV})$, independent of the number of thiophene units in the copolymer. The lack of effect of increasing the number of thiophene units is similar to what is seen with alternating fluorene-thiophene copolymers, ${ }^{52}$ while the singlettriplet splitting is similar to, but possibly slightly higher than, values found with other conjugated polymers. ${ }^{53,54}$

Singlet oxygen quantum yields $\left(\phi_{\Delta}\right)$ were obtained following photolysis of aerated toluene solutions of the copolymers (Table 3 ). The $\phi_{\Delta}$ values were determined by plotting the initial phosphorescence intensity at $1270 \mathrm{~nm}$ as a function of the laser dose and comparing the slope with that obtained with $1 \mathrm{H}$ phenalen-1-one in toluene as the standard.

Photophysical Properties. From the photophysical parameters obtained in solution and in the solid state (Table 3) it can be seen that as a general trend the radiationless processes $\left(\phi_{\mathrm{IC}}\right.$ $+\phi_{\text {ISC }}$, involving in principle isolated polymer chains, are the dominant excited-state deactivation routes in solution for the polymers studied. In contrast, as discussed earlier, in the solid state interactions with the medium play a major role in reducing fluorescence quantum yields. However, from the rate constants presented in Table 3, it is also clear that in all cases radiationless pathways are dominant in the excited-state deactivation.

It is also worth noting that in methylcyclohexane both the $\phi_{\mathrm{F}}$ and $\tau_{\mathrm{F}}$ values slightly decrease relative to toluene (Table 3 ). The only significant difference occurs with $\mathrm{OPhBNp} \alpha 3$ where the $\phi_{\mathrm{F}}$ value in methylcyclohexane decreases ca. $1 / 2$ relative to toluene. This most likely may have its cause in the poor solubility of this polymer in methylcyclohexane. Nevertheless, the radiative and radiationless rate constants are approximately identical in both solvents, thus showing that the same deactivation processes are operative independently of the solvent used. This independence of the solvent properties for the photophysical parameters is characteristic of thiophene-like oligomers and polymers. $^{27}$

In contrast to the behavior found for similar copolymers incorporating oligothiophene segments, in the present case we found that the fluorescence quantum yield $\left(\phi_{\mathrm{F}}\right)$ does not change with the number of thiophenes in the polymer. ${ }^{11} \mathrm{~A}$ similar observation has been found with quinoxaline/oligothiophene copolymers. ${ }^{55}$ It is also worth noting that the $\phi_{\mathrm{F}}$ does not seem to be affected by the introduction of octylbenzyloxy side chains in the 1,1'-binaphthyl spacer instead of octyloxy groups.

Nevertheless, the addition of thienyl units results in a moderate increase in the intersystem-crossing quantum yield $\left(\phi_{\mathrm{T}}\right)$ which is made at the expenses of a decrease in the internal conversion decay processes $\left(\phi_{\mathrm{IC}}=1-\phi_{\mathrm{F}}-\phi_{\mathrm{T}}\right)$. Theoretical studies suggest that intersystem crossing in systems containing thiophene units may result from extensive spin-orbit coupling. ${ }^{56}$ At low temperature the $\phi_{\mathrm{F}}$ values have in general lower values than those obtained at $293 \mathrm{~K}$. The exception occurs with $\mathrm{OPhBNp} \alpha 2$ where no change in the $\phi_{\mathrm{F}}$ value is observed upon going to $77 \mathrm{~K}$. This could be attributed to the fact that the $S_{1}$ state probably has the same geometry as that found at $293 \mathrm{~K}^{57}$ The decrease of the $\phi_{\mathrm{F}}$ values upon lowering the temperature can be associated with an induced conformational change, which is also in agreement with the marked red shift of the absorption and emission spectra compared to $293 \mathrm{~K}$. However, at this stage the possibility of aggregation at low temperature cannot be discarded. The decrease in the $\phi_{\mathrm{F}}$ upon going to $77 \mathrm{~K}$ contrasts with the behavior found for thiophene oligomers (where an increase or constancy of this value was observed), ${ }^{27,33}$ which is in agreement with what has been found with poly[2,6-(1,5dioctylnaphthalene)] thiophenes. ${ }^{11}$

From Table 3 and Figure 1 it can be noted that the $\phi_{\mathrm{F}}$ values in thin films are lower than those obtained in toluene solution at $293 \mathrm{~K}$. This is a general pattern found for $\pi$-conjugated polymers in which the low $\phi_{\mathrm{F}}$ in the solid state are due to the increase of the nonradiative decay processes, which, as discussed 
earlier, results from intermolecular interactions. Again with the copolymers studied, aggregation may be significant as suggested by the red shift and the broadening of the absorption and emission spectra when going from solution to thin films. This result may be associated with increasing intrachain or interchain interaction generated in the solid state of the copolymers.

From Table 3 it can also be seen that singlet oxygen formation yields are very close to the quantum yields for triplet formation, providing support for the latter values and indicating that the efficiency of triplet energy transfer to produce singlet oxygen $\left(S_{\Delta}=\phi_{\Delta} / \phi_{\mathrm{T}}\right)$ is very close to unity. These results suggest that reaction with molecular oxygen may be an important pathway for the deactivation of the triplet state of these copolymers.

\section{Conclusions}

A complete spectral and photophysical investigation of four naphthalene-thiophene copolymers with bithiophene and terthiophene units was carried out in solution and in the solid state. Particular interest is focused on the role of the binaphthyl unit in introducing conjugation breaks into the system, which thus show similarities to naphthalene-thiophene copolymers. For all the polymers studied in solution at room temperature, the fluorescence decay is dominated by nonradiative processes on isolated chains. The data obtained follow previous findings with thiophene-based polymers showing the influence of these units in the emissive properties of the polymers and support the dominant role of the binaphthyl moiety as a conjugation break. However, in contrast with a general trend found where the photophysical parameters $\left(\phi_{\mathrm{F}}\right)$ increases with the incremental contribution of thiophene units, the substitution of a bithiophene $(n=2)$ with a terthiophene $(n=3)$ unit in the polymer does not change the photophysical properties of the polymers. This brings out new developments to the interpretation and full understanding of this behavior. In addition, at low temperatures, a new band is observed in the fluorescence excitation spectra around $520 \mathrm{~nm}$, which may hint at there being some conjugation communication across the binaphthyl linkage. A detailed interpretation of the complex time-resolved fluorescence studies in the picosecond time domain ( 2 ps time resolution) has been made, indicating that only a decay law with three exponentials can properly fit the observed decays. Rise and decay components are associated with the shortest lifetime component at long and short emission wavelengths, respectively, of the polymer spectra and are attributed to intramolecular energy transfer. While conformational relaxation may exist, it is probably outside our observation time window. Steady-state fluorescence anisotropy data indicate that excitation along the absorption spectra of $\mathrm{BNp} \alpha 3$ (used as a representative polymer) leads to a progressive increase in the anisotropy values. This is indicative of the existence of a gradual contribution from more relaxed segments, absorbing and emitting at longer wavelengths.

In solution in the presence of oxygen, singlet oxygen formation is observed, with very similar yields to those of triplet formation. In films and low-temperature glasses, a major contribution to the decrease in fluorescence quantum yields comes from intermolecular interactions with the matrix.

Acknowledgment. Financial support from FEDER and FCT (through Project POCI/QUI/58291/2004) is acknowledged. J. Pina acknowledges FCT for a Ph.D. Grant (SFRH/BD/18876/2004). Drs. S. Navaratnam and R. Edge (FRRF, Daresbury Laboratory) are acknowledged for their excellent technical support in the pulse radiolysis experiments (triplet energy determinations). We also thank Sven K. Weber, Benjamin S. Nehls, Markus Volk, and Tony Farrell for assistance and valuable ideas in some of the preliminary synthetic procedures.

\section{References and Notes}

(1) Chien, C. H.; Shih, P. I.; Wu, F. I.; Shu, C. F.; Chi, Y. J. Polym. Sci., Part A: Polym. Chem. 2007, 45, 2073-2084.

(2) Bhatia, V.; Gupta, D.; Kabra, D.; Narayan, K. S. J. Mater. Sci.: Mater. Electron. 2007, 18, 925-930.

(3) Bundgaard, E.; Krebs, F. C. Sol. Energy Mater. Sol. Cells 2007, 91, 954-985.

(4) Feng, L. H.; Bie, H. Y.; Chen, Z. B. J. Appl. Polym. Sci. 2005, 98, 434-438.

(5) Pu, L. Chem. Rev. 1998, 98, 2405-2494.

(6) Ostrowski, J. C.; Hudack, R. A.; Robinson, M. R.; Wang, S. J.; Bazan, G. C. Chem.-Eur. J. 2001, 7, 4500-4511.

(7) Musick, K. Y.; Hu, Q. S.; Pu, L. Macromolecules 1998, 31, 29332942.

(8) Zotti, G.; Zecchin, S.; Vercelli, B.; Berlin, A.; Casado, J.; Hernandez, V.; Ortiz, R. P.; Navarrete, J. T. L.; Orti, E.; Viruela, P. M.; Milian, B. Chem. Mater. 2006, 18, 1539-1545.

(9) Silcoff, E. R.; Sheradsky, T. Macromolecules 1998, 31, 9116-9120.

(10) Burrows, H. D.; Seixas de Melo, J.; Serpa, C.; Arnaut, L. G.; Monkman, A. P.; Hamblett, I.; Navaratnam, S. J. Chem. Phys. 2001, $115,9601-9606$.

(11) Pina, J.; Seixas de Melo, J.; Burrows, H. D.; Galbrecht, F.; Nehls, B. S.; Farrell, T.; Scherf, U. J. Phys. Chem. C 2007, 111, 7185-7191.

(12) Rabe, T.; Hoping, M.; Schneider, D.; Becker, E.; Johannes, H. H.; Kowalsky, W.; Weimann, T.; Wang, J.; Hinze, P.; Nehls, B. S.; Scherf, U.; Farrell, T.; Riedl, T. Adv. Funct. Mater. 2005, 15, 1188-1192.

(13) Zhan, X. W.; Wang, S.; Liu, Y. Q.; Wu, X.; Zhu, D. B. Chem. Mater. 2003, 15, 1963-1969.

(14) Scheblykin, I. G.; Yartsev, A.; Pullerits, T.; Gulbinas, V.; Sundstrom, V. J. Phys. Chem. B 2007, 111, 6303-6321.

(15) Westenhoff, S.; Beenken, W. J. D.; Friend, R. H.; Greenham, N. C.; Yartsev, A.; Sundstrom, V. Phys. Rev. Lett. 2006, 97.

(16) Di Paolo, R. E.; Seixas de Melo, J.; Pina, J.; Burrows, H. D.; Morgado, J.; Maçanita, A. L. ChemPhysChem 2007, 8, 2657-2664.

(17) Dogariu, A.; Vacar, D.; Heeger, A. J. Phys. Rev. B 1998, 58, 1021810224.

(18) Bjorklund, T. G.; Lim, S. H.; Bardeen, C. J. J. Phys. Chem. B 2001, 105, 11970-11977.

(19) Dias, F. B.; Maçanita, A. L.; Seixas de Melo, J.; Burrows, H. D.; Guntner, R.; Scherf, U.; Monkman, A. P. J. Chem. Phys. 2003, 118, 7119-7126.

(20) Seixas de Melo, J.; Pina, J.; Burrows, H. D.; Di Paolo, R. E.; Maçanita, A. L. Chem. Phys. 2006, 330, 449-456.

(21) Sugimoto, T.; Ebihara, Y.; Ogino, K.; Vacha, M. ChemPhysChem 2007, 8, 1623-1628.

(22) Yaliraki, S. N.; Silbey, R. J. J. Chem. Phys. 1996, 104, 1245-1253.

(23) Gunes, S.; Neugebauer, H.; Sariciftci, N. S. Chem. Rev. 2007, 107, $1324-1338$

(24) Veres, J.; Ogier, S.; Lloyd, G.; de Leeuw, D. Chem. Mater. 2004, 16, $4543-4555$.

(25) Asawapirom, U. G. R.; Forster, M.; Farrell, T.; Scherf, U. Synthesis 2002, 1136-1142.

(26) Nehls, B. S.; Galbrecht, F.; Brauer, D. J.; Lehmann, C. W.; Scherf, U.; Farrell, T. J. Polym. Sci., Part A: Polym. Chem. 2006, 44, 55335545.

(27) Becker, R. S.; Seixas de Melo, J.; Maçanita, A. L.; Elisei, F. J. Phys. Chem. 1996, 100, 18683-18695.

(28) Valeur, B. Molecular Fluorescence: Principles and Applications; Wiley-VCH: Weinheim, 2002.

(29) Pina, J.; Burrows, H. D.; Becker, R. S.; Dias, F. B.; Maçanita, A. L.; Seixas de Melo, J. J. Phys. Chem. B 2006, 110, 6499-6505.

(30) Striker, G.; Subramaniam, V.; Seidel, C. A. M.; Volkmer, A. J. Phys. Chem. B 1999, 103, 8612-8617.

(31) Giestas, L.; Yihwa, C.; Lima, J. C.; Vautier-Giongo, C.; Lopes, A.; Maçanita, A. L.; Quina, F. H. J. Phys. Chem. A 2003, 107, 32633269.

(32) Pina, J.; Seixas de Melo, J.; Burrows, H. D.; Bilge, A.; Farrell, T.; Forster, M.; Scherf, U. J. Phys. Chem. B 2006, 110, 15100-15106.

(33) Seixas de Melo, J.; Silva, L. M.; Kuroda, M. J. Chem. Phys. 2001, $115,5625-5636$.

(34) Asawapirom, U.; Guntner, R.; Forster, M.; Farrell, T.; Scherf, U. Synthesis 2002, 1136-1142.

(35) Nehls, B. S.; Asawapirom, U.; Fuldner, S.; Preis, E.; Farrell, T.; Scherf, U. Adv. Funct. Mater. 2004, 14, 352-356.

(36) Galbrecht, F.; Bunnagel, T. W.; Scherf, U.; Farrell, T. Macromol. Rapid Commun. 2007, 28, 387-394.

(37) Sun, Y.; Li, Y. Z.; Li, Y. Q.; Ma, F. C. Comput. Mater. Sci. 2007, 39, 673-677.

(38) Casado, J.; Miller, L. L.; Mann, K. R.; Pappenfus, T. M.; Higuchi, H.; Orti, E.; Milian, B.; Pou-Amerigo, R.; Hernandez, V.; Navarrete, J. T. L. J. Am. Chem. Soc. 2002, 124, 12380-12388. 
(39) Seixas de Melo, J.; Burrows, H. D.; Svensson, M.; Andersson, M. R.; Monkman, A. P. J. Chem. Phys. 2003, 118, 1550-1556.

(40) Schindler, F.; Jacob, J.; Grimsdale, A. C.; Scherf, U.; Mullen, K.; Lupton, J. M.; Feldmann, J. Angew. Chem., Int. Ed. 2005, 44, 15201525.

(41) Di Paolo, R. E.; Gigante, B.; Esteves, M. A.; Pires, N.; Santos, C.; Lameiro, M. H.; Seixas de Melo, J.; Burrows, H. D.; Maçanita, A. L. ChemPhysChem 2008, 9, 2214-2220.

(42) Scholes, G. D. Annu. Rev. Phys. Chem. 2003, 54, 57-87.

(43) Heun, S.; Mahrt, R. F.; Greiner, A.; Lemmer, U.; Bassler, H.; Halliday, D. A.; Bradley, D. D. C.; Burn, P. L.; Holmes, A. B. J. Phys.: Condens. Matter 1993, 5, 247-260.

(44) Meskers, S. C. J.; Hubner, J.; Oestreich, M.; Bassler, H. J. Phys. Chem. B 2001, 105, 9139-9149.

(45) Bredas, J. L.; Beljonne, D.; Coropceanu, V.; Cornil, J. Chem. Rev. 2004, 104, 4971-5003.

(46) Hintschich, S. I.; Dias, F. B.; Monkman, A. P. Phys. Rev. B 2006, 74.

(47) Lap, D. V.; Grebner, D.; Rentsch, S.; Naarmann, H. Chem. Phys. Lett. 1993, 211, 135-139.

(48) Oelkrug, D.; Egelhaaf, H. J.; Gierschner, J.; Tompert, A. Synth. Met. 1996, 76, 249-253.

(49) Dexter, D. L. J. Chem. Phys. 1953, 21, 836-850.
(50) Dias, F. B.; Morgado, J.; Maçanita, A. L.; da Costa, F. P.; Burrows, H. D.; Monkman, A. P. Macromolecules 2006, 39, 5854-5864.

(51) Burrows, H. D.; Seixas de Melo, J.; Serpa, C.; Arnaut, L. G.; Miguel, M. d. G.; Monkman, A. P.; Hamblett, I.; Navaratnam, S. Chem. Phys. 2002, 285, 3-11.

(52) Fonseca, S. M.; Pina, J.; Arnaut, L. G.; Seixas de Melo, J.; Burrows, H. D.; Chattopadhyay, N.; Alcácer, L.; Charas, A.; Morgado, J.; Monkman, A. P.; Asawapirom, U.; Scherf, U.; Edge, R.; Navaratnam, S. J. Phys. Chem. B 2006, 110, 8278-8283.

(53) Monkman, A. P.; Burrows, H. D.; Hartwell, L. J.; Horsburgh, L. E.; Hamblett, I.; Navaratnam, S. Phys. Rev. Lett. 2001, 86, 1358-1361.

(54) Kohler, A.; Beljonne, D. Adv. Funct. Mater. 2004, 14, 11-18.

(55) Tsami, A.; Bunnagel, T. W.; Farrell, T.; Scharber, M.; Choulis, S. A.; Brabec, C. J.; Scherf, U. J. Mater. Chem. 2007, 17, 1353-1355.

(56) Beljonne, D.; Shuai, Z.; Pourtois, G.; Bredas, J. L. J. Phys. Chem. A 2001, 105, 3899-3907.

(57) Seixas de Melo, J.; Pina, J.; Burrows, H. D.; Brocke, S.; Herzog, O.; Thorn-Csanyi, E. Chem. Phys. Lett. 2004, 388, 236-241.

MA802395C 